ORIGINAL ARTICLE

\title{
Is being overweight associated with behavioural problems in childhood and adolescence? Findings from the Mater-University study of pregnancy and its outcomes
}

\author{
D A Lawlor, A A Mamun, M J O'Callaghan, W Bor, G M Williams, J M Najman
}

Arch Dis Child 2005;90:692-697. doi: 10.1136/adc.2004.062919

See end of article for authors' affiliations

Correspondence to: Dr D A Lawlor, Department of Social Medicine University of Bristol Canynge Hall, Whiteladies Road, Bristol BS8 2PR, UK; d.a.lawlor@bristol.ac.uk

Accepted 24 January 2005 Published Online First 26 April 2005

\begin{abstract}
Aims: To examine the associations between being overweight and behavioural problems at ages 5 and 14 . Methods: Birth cohort study of 2875 individuals who were born in Brisbane between 1981 and 1984 and who were followed up at ages 5 and 14 years. Behavioural problems were defined as scoring above the 90th centile on Achenbach's child behavioural checklist.

Results: In cross-sectional analyses there was no association between being overweight and behavioural problems in either females at age 5. At age 14 females who were overweight were more likely than those who were normal weight to experience behavioural problems. However, there was no association between being overweight and behavioural problems at age 14 among males. The prevalence of behavioural problems increased linearly across the distribution of body mass index in females at age 14. In prospective analyses, among participants who had no behavioural problems at age 5, there was no association between being overweight at age 5 and behavioural problems at age 14 in either sex. Females who were overweight at age 5 and normal weight at age 14 had reduced odds of behavioural problems at age 14.

Conclusions: Among adolescent females there is a positive linear association between body size and behavioural problems. However, no such association was found in adolescent males, or in either sex at age 5 years, and in prospective analyses being overweight at age 5 was not associated with behavioural problems in either sex at age 14.
\end{abstract}

T he population prevalence of childhood obesity has increased by about threefold in most industrialised countries over the last 10-20 years. ${ }^{12}$ These trends are likely to have major public health consequences. ${ }^{12}$ Obesity tracks from childhood to adulthood and there is emerging evidence that the precursors for diabetes and cardiovascular disease, some of which will be irreversible, already exist in obese children..$^{3-5}$ In addition to these long term consequences on cardiovascular health being obese may be associated with psychological morbidity, though studies in this area have reported conflicting results. ${ }^{67}$

There is evidence going back to the 1960s that children as young as 6-10 years old stereotype, have negative perceptions of, and do not want to be friends with, other children who are overweight or obese. ${ }^{89}$ Recent studies have confirmed similar findings in contemporary children. ${ }^{10}{ }^{11}$ Despite these findings, studies of the associations of body size with measures of psychological distress have been inconsistent, ${ }^{6712}$ with several reviews concluding that there is no association between body size and psychological distress. ${ }^{13-15}$ Others have pointed out that given the heterogeneous nature of the aetiology of both obesity and psychological distress, inconsistencies between studies are to be expected and future work should consider whether associations exist in particular groups. ${ }^{16}$ For example, one might expect a gender difference in the association since females are considerably more likely than males to seek treatment for obesity (despite similar a prevalence in each gender) and there is some evidence that obesity carries more stigma in females compared to males. ${ }^{16}$ Most studies to date have been in adult populations. ${ }^{67}$ However, adolescents may be another group for whom body size is particularly associated with psychological distress. ${ }^{16}$ Most studies to date, in all age groups, have been cross-sectional and therefore cannot determine whether being overweight results in psychological distress or whether this resulted in being overweight. ${ }^{12}{ }^{16}$ Further, cross-sectional studies cannot examine the effect of changes in overweight status over time on the occurrence of psychological outcomes.

Preventing psychological distress in childhood and adolescence is important. Further, if being overweight or obese is associated with psychological distress this in turn may affect the ability of a child to respond to health promoting advice and lose weight. ${ }^{7}$ Thus a spiral of increasing body size and distress may begin in early life. It is important therefore to determine whether being overweight or obese is associated with psychological distress in early life.

The aims of this study are to examine the associations between being overweight and behavioural problems at ages 5 and 14, to determine whether associations vary by gender, and to examine whether change in overweight status between ages 5 and 14 is associated with behavioural problems at age 14. We used the Achenbach Child Behavior Checklist (CBCL), which is a widely used, standardised, empirically based parental report instrument designed to assess behavioural problems and competencies of children aged 4-16 years. ${ }^{17}$ The CBCL has been shown to predict future academic progress and mental distress including suicide and diagnoses of depression and psychosis. ${ }^{18}$

\section{METHODS}

\section{Participants}

The Mater-University study of pregnancy and its outcomes (MUSP) is a prospective study of women, and their offspring, who received antenatal care at a major public hospital (Mater Misericordiae Hospital) in South Brisbane between 1981 and 1984. ${ }^{19}$ The cohort consists of 7223 women (and their 
offspring) who delivered a live singleton baby, who neither died nor was adopted prior to leaving hospital, and who completed both initial phases of data collection; this represents $87 \%$ of all women who attended the antenatal clinic during the study period.

These mothers and children have been followed up prospectively with mothers completing questionnaires at their first antenatal clinic visit, 3-5 days after birth, 6 months after birth, 5 years, and 14 years after birth. In addition, at ages 5 and 14 detailed physical, behavioural, and developmental examinations of the children were undertaken and at 14 years the children completed health, welfare, and lifestyle questionnaires.

\section{Measurements of exposures and outcomes}

At both ages the average of two measures of the child's weight, lightly clothed, with a scale accurate to $0.2 \mathrm{~kg}$ was used. Height was measured using a portable stadiometer on both occasions. Body mass index was calculated as the individual's weight in kilograms divided by the square of their height in metres. Overweight and obesity were defined according to standard definitions derived from international surveys by Cole and colleagues. ${ }^{20}$ Too few of the participants fell into the obese categories for meaningful analyses (table 1) therefore we classified children as either overweight (equal to or above the overweight threshold, including those who were above the obese threshold) or normal weight (below the overweight threshold) for the main analyses presented in this paper. In this study the participants were defined as overweight at age 5 if their body mass index was greater than $17.42 \mathrm{~kg} / \mathrm{m}^{2}$ for males and $17.15 \mathrm{~kg} / \mathrm{m}^{2}$ for females and were defined as overweight at age 14 if their body mass index exceeded $22.62 \mathrm{~kg} / \mathrm{m}^{2}$ for males and $23.34 \mathrm{~kg} / \mathrm{m}^{2}$ for females. These values are equivalent to exceeding $25 \mathrm{~kg} / \mathrm{m}^{2}$ in adulthood. ${ }^{20}$

Child behavioural problems were assessed from maternal reports of child behaviour using modified versions of Achenbach's CBCL at ages 5 and $14 .{ }^{17}$ The CBCL is a widely used, standardised, empirically based parental report instrument designed to assess behavioural problems and competencies of children aged 4-16 years. ${ }^{17}$ Separate editions of the instrument have been standardised for both males and females aged 4-5, 6-11, and 12-16, and we used the sex specific 4-5 year old instrument at age 5 and the 12-16 year instrument at age 14. The CBCL has been shown in a number of studies to have construct validity and a large longitudinal study of children with at least one "sign of disturbance" on the CBCL found high predictive value for later social, academic, emotional, and behaviour problems (including suicide and clinical neurotic and psychotic mental health diagnoses), ${ }^{18}$ suggesting that the CBCL is a valid and reliable indicator of clinically significant psychological dysfunction. Though we recognise that our definition of behavioural problems using the CBCL is not the same as a clinical diagnosis of behavioural problems for ease of reading we refer to those with scores above the 90th centile as having behavioural problems. At age 14 the question concerning somatic behaviours was worded differently to that used originally by Achenbach. In his original questionnaire Achenbach asked about the occurrence of a number of symptoms in the following way: "how often has your child had the following in the last six month, without known medical cause?"; the question was followed by a list of symptoms, including, for example, dizziness, overtired, aches and pains, etc. In our version of this question the statement "without known medical cause" was omitted. In this paper we are concerned with the broad outcome of a high score on the total checklist rather than with specific responses to individual questions. However, we repeated all analyses with the response to the somatic question omitted and only other questions (relating to depression/anxiety/withdrawal/ aggressive behaviours/speech problems/sleeping difficulty) included. This allowed us to determine whether any of our results were being driven by the somatic scale, which may be less representative of psychological distress in the way that we asked it compared to Achenbach's original intention. The results from that analysis did not differ from those presented here.

Pubertal status was assessed using Tanner's classification. ${ }^{21}$ Participants were shown pictures of breasts and genitalia representative of Tanner's classification and asked to report the best picture of their current status of development. Parental body mass indices were estimated from maternal self-report of her pre-pregnancy height and weight and that of her child's father's height and weight at the study initiation. There was a high level of correlation between maternal estimate of her pre-pregnancy weight and her measured weight on the first antenatal visit (Pearson's correlation coefficient $=0.95)$. Maternal age at the child's birth was obtained from obstetric records and parental education was obtained from interviews with the mother at the study initiation. At the 5 and 14 year follow ups the

Table 1 Prevalence of overweight and obesity according to adult equivalent thresholds at aged 5 and 14 among participants in the Mater-University Study of Pregnancy and its Outcomes $(n=2875)$

\begin{tabular}{|c|c|c|c|c|}
\hline & \multicolumn{4}{|c|}{ Number (\%) [\% from 1995 Australian National Nutritional Survey for similar age category]* } \\
\hline & \multicolumn{2}{|l|}{ Age 5} & \multicolumn{2}{|l|}{ Age 14} \\
\hline & Females $(n=1377)$ & Males $(n=1498$ ) & Females $(n=1377)$ & Males $(n=1498)$ \\
\hline $\begin{array}{l}\text { Normal weight* } \\
\text { Overweight* } \\
\text { Obese* }^{*} \\
\text { Either overweight or obese }\end{array}$ & $\begin{array}{l}1112(80.8) \\
205(14.9)[16.5] \\
60(4.4)[6.1] \\
265(19.3)[22.6]\end{array}$ & $\begin{array}{l}1265(84.4) \\
194(13.0)[10.4] \\
39(2.6)[3.0] \\
233(15.6)[13.4]\end{array}$ & $\begin{array}{l}1059(76.8) \\
319(23.2)[14.5] \\
0[4.4] \\
319(23.2)[18.9]\end{array}$ & $\begin{array}{l}1187(79.2) \\
246(16.4)[20.0] \\
65(4.3)[6.1] \\
319(20.7)[26.1]\end{array}$ \\
\hline \multicolumn{5}{|c|}{$\begin{array}{l}\text { *Percentage in each category for Australian children aged } 4-6 \text { years (in the age } 5 \text { cells) and aged 12-15 years (in the age } 14 \text { cell) from the } 1995 \text { Australian } \\
\text { National Nutritional Survey. } \\
\text { *At age 5: } \\
\text { Normal weight BMI }<17.15 \mathrm{~kg} / \mathrm{m}^{2} \text { for females and }<17.42 \mathrm{~kg} / \mathrm{m}^{2} \text { for males. } \\
\text { Overweight } \mathrm{BMI} \geqslant 17.15 \mathrm{~kg} / \mathrm{m}^{2} \text { and }<19.17 \mathrm{~kg} / \mathrm{m}^{2} \text { for females and } \geqslant 17.42 \mathrm{~kg} / \mathrm{m}^{2} \text { and }<19.30 \mathrm{~kg} / \mathrm{m}^{2} \text { for males. } \\
\text { Obese BMI } \geqslant 19.17 \mathrm{~kg} / \mathrm{m}^{2} \text { for females and } \geqslant 19.30 \mathrm{~kg} / \mathrm{m}^{2} \text { for males. } \\
\text { At age } 14 \text { : } \\
\text { Normal weight BMI }<23.34 \mathrm{~kg} / \mathrm{m}^{2} \text { for females and }<22.62 \mathrm{~kg} / \mathrm{m}^{2} \text { for males. } \\
\text { Overweight BMI } \geqslant 23.34 \mathrm{~kg} / \mathrm{m}^{2} \text { and }<28.57 \mathrm{~kg} / \mathrm{m}^{2} \text { for females and } \geqslant 22.62 \mathrm{~kg} / \mathrm{m}^{2} \text { and }<27.63 \mathrm{~kg} / \mathrm{m}^{2} \text { for males. } \\
\text { Obese BMI } \geqslant 28.57 \mathrm{~kg} / \mathrm{m}^{2} \text { for females and } \geqslant 27.63 \mathrm{~kg} / \mathrm{m}^{2} \text { for males. } \\
\text { For both ages these thresholds are based on work by Cole et a }{ }^{20} \text { and are the childhood equivalents of the adult thresholds of } 25 \mathrm{~kg} / \mathrm{m}^{2} \text { and } 30 \mathrm{~kg} / \mathrm{m}^{2} \text { used to } \\
\text { define overweight and obesity in adulthood. }\end{array}$} \\
\hline
\end{tabular}


mothers were asked to indicate gross family income for the previous year in seven pre-specified categories. In the analyses presented here these were collapsed into three categories: low, \$\$AU15 599; middle, \$AU15 600-25 999; and high, $\geqslant \$ A U 26000$ per annum when the child was aged 5 years; and low, \$\$AU25 999; middle, \$AU26 000-36 499; and high, $\geqslant \$ A U 36500$ per annum when the child was aged 14.

\section{Statistical analyses}

Multiple logistic regression was used to assess cross-sectional and prospective associations of overweight/obese and body mass index (as a continuous variable) with behavioural problems. In the prospective analyses those with behavioural problems at age 5 were excluded so that the association of being overweight at age 5 with the occurrence of new (incident) cases of behavioural problems could be ascertained. If those with behavioural problems at age 5 were included in these prospective analyses any associations might be explained by the persistence of behavioural problems over time rather than by our exposure of being overweight. Adjustment was made for the following potential confounding factors: age (continuous variable in days), family income (3-level categorical variable), Tanner's score of pubertal development (3-level categorical variable), maternal age at the child's birth (3-level categorical variable), parental education (3-level categorical variables), parental body mass index (continuous variable). Likelihood ratio tests were used to test for linear trends and to determine whether there was an interaction between gender and being overweight in any of the associations. Non-linear associations of body mass index with behavioural problems were assessed by including a quadratic term in the regression models. All analyses were conducted using Stata version 8.0 (Stata Inc., Texas).

\section{RESULTS}

Of the 7223 participants in the original cohort, 2875 (40\%) had complete data on body mass index and the behavioural checklist at both ages 5 and 14; this consisted of 1377 females and 1498 males. As reported previously loss to follow up was selective with those who did not have 5 and 14 year old follow up data being more likely to have been from low income families at the time of birth, to have had younger aged mothers at birth and mothers who smoked during their pregnancy. ${ }^{22}$ All analyses in this study are based only on these 2875 with complete data. Table 1 shows the prevalence of overweight and obesity among these 2875 children together with similar prevalences for children aged 4-6 (used as a comparator for the MUSP children when they were aged 5) and those aged 12-15 (used as a comparator for the MUSP participants when they were aged 14) taken from the 1995 Australian National Nutrition Survey, a nationally representative sample. ${ }^{23}$ Total prevalences of either overweight or obese were similar in our study population to those in the national survey, though there were fewer obese children in each age and sex category in our study sample. Table 2 shows the characteristics of those included in the analyses.

\section{Cross-sectional associations of body mass index with behavioural problems at ages 5 and 14}

In cross-sectional analyses there was no association between being overweight and behavioural problems in either females (odds ratio 1.05; 95\% CI 0.68 to 1.61) or males (1.07; 95\% CI 0.68 to 1.67 ) at age 5 . At age 14 females who were overweight were more likely than those who were normal weight to experience behavioural problems $(2.10 ; 95 \%$ CI 1.41 to 3.14$)$. However, there was no association between being overweight and behavioural problems at age 14 among males (1.19; $95 \%$ CI 0.81 to 1.76 ); $p=0.004$ for interaction with gender in the association between being overweight/obese and behavioural problems.

Among female participants with complete data on all covariates ( $\mathrm{n}=1245$; $90 \%$ of females who were followed up and included in the main analyses presented above), the unadjusted association between being overweight and behavioural problems was 2.19 (95\% CI 1.51 to 3.32), which is consistent to that presented above. With adjustment for age, pubertal stage, maternal age at birth, ethnicity, parental education, family income, and parental body mass index this attenuated to 2.03 (95\% CI 1.26 to 3.25 ), but a positive association remained.

The prevalence of behavioural problems increased linearly across the distribution of body mass index in females at age 14 (fig 1A). No such association was seen for males at age 14 (fig $1 \mathrm{~B}$ ); $\mathrm{p}=0.01$ for difference (interaction) in this linear effect between males and females. Each one standard deviation increase in body mass index at age 14 for females was associated with a 32\% increased odds of behavioural problem (odds ratio 1.32; 95\% CI 1.08 to 1.61) with full adjustment. In males the fully adjusted odds ratio of behavioural problems for a one standard deviation increase in body mass index was 1.06 (95\% CI 0.88 to 1.29 ); $\mathrm{p}=0.18$ for interaction with gender in these models. When quadratic terms were added to these models there was no evidence of non-linear associations in either sex ( $\mathrm{p}>0.4$ for both).

\section{Prospective associations of body mass index at age 5 and behavioural problems at age 14}

Among participants who had no behavioural problems at age 5 there were no associations between being overweight at age 5 in either sex, and behavioural problems and age 14 and body mass index at age 5 entered into models as a continuous variable were not associated with behavioural problems at age 14 in either sex (all $\mathrm{p}>0.5$ ).

Table 3 shows the cumulative association of being overweight at ages 5 and 14 with behavioural problems at age 5 among those who had no behavioural problems at age 5 . Although imprecise among females, those who were overweight at age 5 and normal weight at age 14, compared to those who were normal weight at both ages tended to have reduced odds of behavioural problems. As expected from the cross-sectional analyses, those who were normal weight at age 5 and overweight at age 14 and those who were overweight at both ages had increased odds of behavioural problems at age 14. Among males the odds of behavioural problems were somewhat lower among those who were overweight at age 5 but then normal weight at age 14, but in general the odds ratios were similar for each category of overweight status at the two ages in males.

\section{DISCUSSION}

We have found in cross-sectional analyses that females who are overweight at age 14 have increased odds of behavioural problems compared to those who are not overweight. Further, there was a linear trend of increasing behavioural problems with increasing body mass index across the distribution of body mass index. This positive linear association between body mass index and behavioural problems among females was independent of a range of potential confounding. We found no evidence of an association between being overweight and behavioural problems at age 5 and no clear associations in males. In prospective analyses being overweight at age 5 was not associated with behavioural problems at age 14 in either sex. For females there was some suggestion that in those who had been 
Table 2 Characteristics of study participants $(n=2875)$

\begin{tabular}{|c|c|c|}
\hline Characteristics & Females $(n=1377)$ & Males $(n=1498)$ \\
\hline \multicolumn{3}{|l|}{ Body mass index at age 5} \\
\hline Mean (SD) & $16.0(1.7)$ & $16.1(1.4)$ \\
\hline $\mathrm{n}(\%)$ overweight/obese & $265(19.2)$ & $233(15.6)$ \\
\hline \multicolumn{3}{|l|}{ Body mass index at age 14} \\
\hline Mean (SD) & $21.1(4.0)$ & $20.2(3.5)$ \\
\hline $\mathrm{n}(\%)$ overweight/obese & $319(23.2)$ & $311(20.8)$ \\
\hline \multicolumn{3}{|l|}{ Symptoms of behavioural problems at age 5} \\
\hline $\mathrm{n}(\%)>90$ th centile on $\mathrm{CBCL}$ & $74(5.4)$ & $112(7.5)$ \\
\hline \multicolumn{3}{|l|}{ Symptoms of behavioural problems at age 14} \\
\hline $\mathrm{n}(\%)>90$ th centile on $\mathrm{CBCL}$ & $116(8.4)$ & $162(10.8)$ \\
\hline \multicolumn{3}{|l|}{ Tanner's pubertal stage } \\
\hline $\mathrm{n}(\%)$ stage $1-2$ & $62(4.5)$ & $197(13.3)$ \\
\hline $\mathrm{n}(\%)$ stage 3 & $493(36.0)$ & $660(44.7)$ \\
\hline $\mathrm{n}(\%)$ stage $4-5$ & $814(59.5)$ & $620(42.0)$ \\
\hline \multicolumn{3}{|l|}{ Ethnicity } \\
\hline White & 1243 (92.5) & $1349(92.6)$ \\
\hline Asian & $46(3.4)$ & $56(3.8)$ \\
\hline Aboriginal or Pacific Islander & $55(4.1)$ & $52(3.6)$ \\
\hline \multicolumn{3}{|l|}{ Age mother at birth } \\
\hline $\mathrm{n}(\%) 13-19$ years & $139(10.1)$ & $156(10.4)$ \\
\hline $\mathrm{n}(\%) 20-34$ years & $1171(85.0)$ & $1252(83.6)$ \\
\hline $\mathrm{n}(\%) \geqslant 35$ years & $67(4.9)$ & $90(6.0)$ \\
\hline \multicolumn{3}{|l|}{ Maternal education } \\
\hline $\mathrm{n}(\%)$ not completing secondary school & $245(17.0)$ & $228(15.3)$ \\
\hline $\mathrm{n}(\%)$ completed secondary school & $884(61.4)$ & $978(62.7)$ \\
\hline $\mathrm{n}(\%)$ higher or further education & $311(21.6)$ & $293(21.5)$ \\
\hline \multicolumn{3}{|l|}{ Paternal education } \\
\hline $\mathrm{n}(\%)$ not completing secondary school & $235(17.8)$ & $245(17.0)$ \\
\hline $\mathrm{n}(\%)$ completed secondary school & $812(61.3)$ & $884(61.4)$ \\
\hline $\mathrm{n}(\%)$ higher or further education & $277(20.9)$ & $311(21.6)$ \\
\hline \multicolumn{3}{|l|}{ Family income at 14 year follow up } \\
\hline n (\%) low & $404(30.0)$ & $444(30.3)$ \\
\hline $\mathrm{n}(\%)$ medium & $399(29.6)$ & $430(29.4)$ \\
\hline $\mathrm{n}(\%)$ high & $546(40.5)$ & $591(40.3)$ \\
\hline \multicolumn{3}{|l|}{ Maternal body mass index } \\
\hline Mean (SD) kg/m $/ \mathrm{m}^{2}$ & $22.0(4.2)$ & $22.0(3.9)$ \\
\hline \multicolumn{3}{|l|}{ Paternal body mass index } \\
\hline Mean (SD) kg/m $\mathrm{m}^{2}$ & $23.8(3.5)$ & $23.8(3.6)$ \\
\hline
\end{tabular}

overweight at age 5 and then normal weight at age 14, behavioural problems were less likely than in those who were overweight at both ages. This may reflect a positive psychological response to relative weight loss among females. However, since this estimate was imprecise, further work, in larger studies, is required to confirm this finding. The lack of an association in prospective analyses may be because crosssectional associations are due to reverse causality, with poor psychological adjustment resulting in weight gain. Alternatively the 9 year gap between age 5 and 14 may be too long to establish a causal association with an effect over a shorter duration.

A number of related mechanisms might explain the link between being overweight and behavioural problems among adolescent females, including stigmatisation and the response to negative perceptions from one's peers, and body dissatisfaction related not only to peers but to a wider perception of acceptable appearance. ${ }^{2}$ If the effect of being overweight on behavioural problems were related to stigmatisation and negative perceptions from one's peers, then this effect may diminish relatively quickly over time once the child had lost weight. Body dissatisfaction, which is often described as "normative" among women in contemporary western society, particularly among adolescent and young adult samples, ${ }^{24-26}$ is more prevalent among those who are overweight. ${ }^{27}$ The longer a female has been overweight the worse her body dissatisfaction tends to be, ${ }^{27}$ and a study among obese adults found that those who were obese by age 16 years, compared to those whose obesity developed at a later age, were more likely to experience body dissatisfaction and low self esteem in adulthood. ${ }^{28}$ However, body dissatisfaction tends to emerge in late childhood and adolescence, ${ }^{24-26}$ and therefore being overweight at age 5 may not be related to body dissatisfaction to the same degree a being overweight at an older age.

\section{Study limitations}

Data on body mass index and behavioural problems at ages 5 and 14 were only available on $40 \%$ of the original cohort, and those without these data were more likely to be from poorer family backgrounds, have younger mothers, and have mothers who smoked throughout their pregnancy. ${ }^{22}$ Despite this loss to follow up, the prevalence of overweight or obesity in this sample was consistent with national data (table 1). The slightly lower prevalence of obesity in each age and sex category in this sample compared to the national sample may be due to the more obese children being lost to follow up in our sample or may reflect geographical or temporal variations. Our results would only be biased if the associations we have presented here were either non-existent or in the opposite direction among those who were not examined at ages 5 and 14. That is to say, among the non-responders one would need to imagine that overweight females had reduced, or similar, odds of behavioural problems to those who were not overweight for our results to be biased. While we cannot rule out this possibility it seems unlikely. Our assessment of Tanner's pubertal stage was not done by trained professionals but was done by asking the participants to rate their own secondary sexual characteristics against pictorial representations of Tanner's scale. This may be inaccurate and may therefore mean that we have not fully adjusted for pubertal status in our associations. 

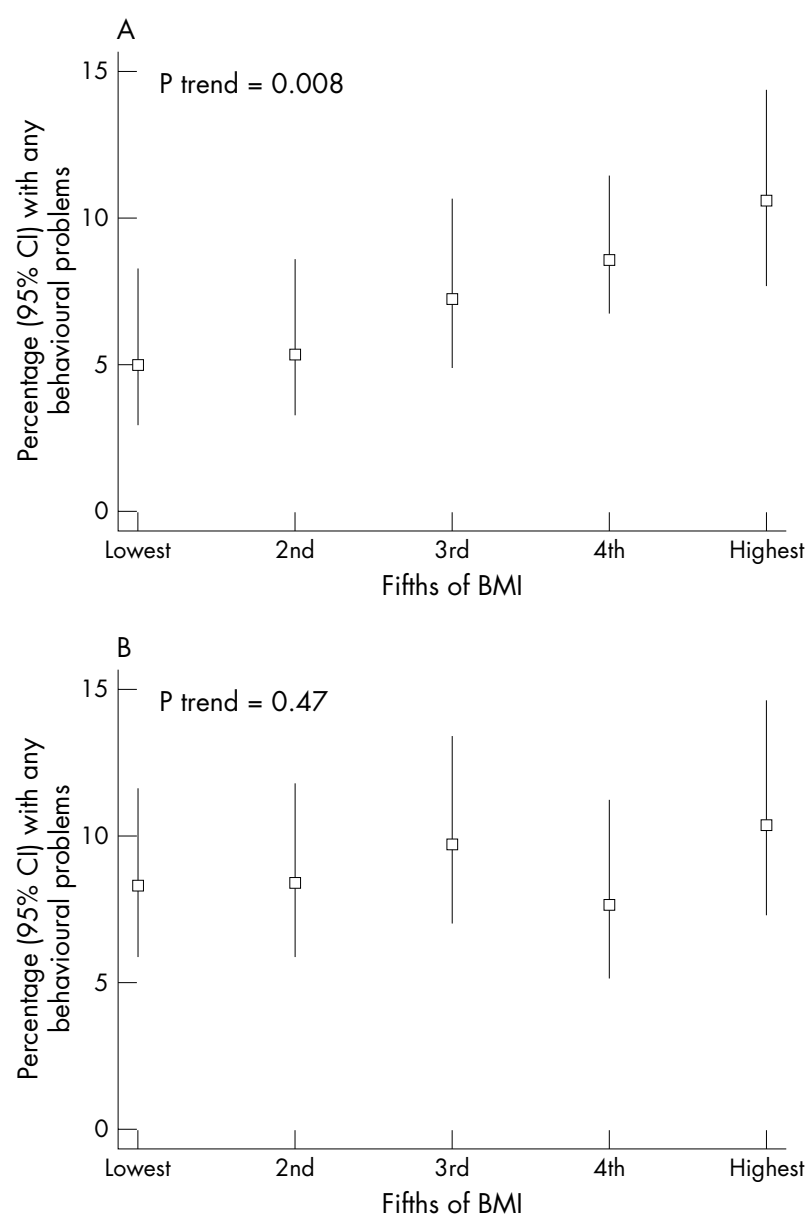

Figure 1 Unadjusted prevalence of behavioural problems by fifths of body mass index distribution among (A) females and (B) males aged 14 .

We attempted to determine the causal direction of the association by assessing the association of overweight status at age 5 with behavioural problems at age 14 and found no association. However, since the time between the two follow up periods covers nine years we cannot rule out the possibility that with a shorter period of follow up a positive association may have been detected. A prospective study in adults aged 46 years and older found that obesity was associated with subsequent depression over a follow up period of one year. ${ }^{29}$ Had we data on shorter periods of follow up we may have found a prospective association.

Although our cross-sectional analyses suggest that body mass index is not associated with behavioural problems in early childhood, since we only have information at two time points - when the children were aged 5 years and 14 yearsit is impossible to determine from this study at what age among females the associations between being overweight and behavioural problems first develop.

\section{Implications}

Although much concern has been expressed about the epidemic of obesity among children and adolescents with respect to the consequences that this has for future development of diabetes and cardiovascular disease, at the actual time of adolescence psychological problems may be one of the main health consequence of overweight or obesity. ${ }^{1}$ Previous studies, which have reported inconsistent results, have largely been in adult populations, have rarely formally assessed whether associations differ between females and males (despite plausible reasons for them doing so) and have largely been cross-sectional. ${ }^{72}{ }^{16}$ Our findings add to this previous work by examining associations in childhood and adolescence, determining whether there is statistical evidence for gender differences in any associations and examining the association prospectively.

Although our results cannot determine with certainty whether the cross-sectional association among females at age 14 is largely due to being overweight leading to psychological distress or vice versa, it is important in clinical practice to acknowledge this association (irrespective of its causal direction). Psychological distress may have a negative impact on weight reduction interventions aimed at adolescents who are overweight or obese, and may as a consequence prevent weight loss and hence increase the future risk of chronic diseases associated with being overweight or obese. ${ }^{7}$ These findings suggest that psychological distress should be considered as a co-morbidity of overweight at this age and that programmes aimed at weight reduction in adolescence need to incorporate elements that deal with psychological symptoms.

Table 3 Association of overweight status at ages 5 and 14 with behavioural problems at age 14 among those free of behavioural problems at age 5 and with complete data on all covariates $(n=2430)$

\begin{tabular}{|c|c|c|c|c|}
\hline & \multicolumn{2}{|c|}{$\begin{array}{l}\text { Odds ratio }(95 \% \mathrm{Cl}) \text { of behavioural problems in females } \\
(\mathrm{n}=1178)\end{array}$} & \multicolumn{2}{|c|}{$\begin{array}{l}\text { Odds ratio }(95 \% \mathrm{Cl}) \text { of behavioural problems in males } \\
(n=1252)\end{array}$} \\
\hline & Unadjusted & Adjusted* & Unadjusted & Adjusted* \\
\hline $\begin{array}{l}\text { Normal weight both ages } \\
n=824 \text { females } \\
n=932 \text { males }\end{array}$ & 1 & 1 & 1 & 1 \\
\hline $\begin{array}{l}\text { Overweight at } 5 \text {, normal at } 14 \\
n=97 \text { females } \\
n=76 \text { males }\end{array}$ & 0.16 (0.02 to 1.15$)$ & 0.14 (0.02 to 1.03$)$ & 0.65 (0.23 to 1.83 ) & $0.56(0.20$ to 1.65$)$ \\
\hline $\begin{array}{l}\text { Normal at } 5 \text {, overweight at } 14 \\
n=133 \text { females } \\
n=134 \text { males }\end{array}$ & 1.75 (0.94 to 3.25 ) & 1.70 (0.87 to 3.27$)$ & 0.93 (0.46 to 1.84 ) & 0.87 (0.42 to 1.78 ) \\
\hline $\begin{array}{l}\text { Overweight at both ages } \\
n=124 \text { females } \\
n=110 \text { males }\end{array}$ & 1.46 (0.74 to 2.89 ) & 1.35 (0.64 to 2.84$)$ & $1.36(0.71$ to 2.60$)$ & $1.10(0.54$ to 2.20$)$ \\
\hline
\end{tabular}

*Adjusted for age (in days) of the children at 14 year follow up, mother's age at birth of child, maternal and paternal education, ethnicity, Tanner's score of pubertal development, maternal and paternal body mass index, and family income.

$\mathrm{Cl}$, confidence interval. 


\section{What is already known on this topic}

- Evidence regarding the association of being overweight with psychological distress in children and adolescents is unclear

In our study we found no association between body mass index and behavioural problems among males. However, this does not necessarily mean that body image is not an important concern for males. Rather it is more likely that striving for different body ideals that are not described by body mass index, such as broad chests and muscular appearance, is a potential source of distress among males.

We suggest that further work in this area should examine prospective associations between body size and behavioural problems measured at repeated short intervals over time in large population samples of children and adolescents.

\section{ACKNOWLEDGEMENTS}

We are grateful to all participants in the study. Greg Shuttlewood, University of Queensland, helped with data management for the study.

\section{Authors' affiliations}

D A Lawlor, Department of Social Medicine, University of Bristol, UK A A Mamun, G M Williams, J M Najman, School of Population Health, University of Queensland Medical School, Brisbane, Australia M J O'Callaghan, W Bor, Child Development and Rehabilitation Services, Mater Children's Hospital, Brisbane, Australia J M Najman, School of Social Science, University of Queensland, Brisbane, Australia

Funding: The core study was funded by the National Health and Medical Research Council (NHMRC) of Australia. This work was funded by the NHMRC (grant number: 252834) and carried out at The University of Queensland and The Mater Hospital. DAL is funded by a (UK) Department of Health Career Scientist Award. The views expressed in the paper are those of the authors and not necessarily those of any funding body.

Competing interests: none

\section{REFERENCES}

1 Ebbeling CB, Pawlak DB, Ludwig DS. Childhood obesity: public-health crisis, common sense cure. Lancet 2002;360:473-81.

2 Lobstein T, Baur L, Uauy R. Obesity in children and young people: a crisis in public health. Obes Rev 2004;5(suppl 1):4-85.

3 Srinivasan SR, Myers L, Berenson GS. Predictability of childhood adiposity and insulin for developing insulin resistance syndrome (syndrome X) in young adulthood: the Bogalusa Heart Study. Diabetes 2002;51:204-9.

4 Ferguson MA, Gutin B, Owens S, et al. Fat distribution and hemostatic measures in obese children. Am J Clin Nutr 1998;67:1136-40.

5 Tounian P, Aggoun Y, Dubern B, et al. Presence of increased stiffness of the common carotid artery and endothelial dysfunction in severely obese children: a prospective study. Lancet 2001;358:1400-4.

6 Stunkard AJ, Sobal J. Psychosocial consequences of obesity. In: Brownell KD, Fairburn CG, eds. Eating disorders and obesity: a comprehensive handbook. New York: Guildford, 1995:417-21.

7 Zametkin AJ, Zoon CK, Klein HW, et al. Psychiatric aspects of child and adolescent obesity: a review of the past 10 years. J Am Acad Child Adolesc Psychiatry 2004;43:134-50

\section{What this study adds}

- Among females, but not males, there is a graded linear association between body mass index and behavioural problems at age 14

- There is no association between body mass index and behavioural problems at age 5 in either sex

- In prospective analyses, body mass index at age 5 was not associated with behavioural problems at age 14

8 Staffieri JR. A study of social stereotype of body image in children. J Pers Soc Psychol 1967;7:101-4.

9 Richardson SA, Hastorf AH, Goodman N, et al. Cultural uniformity in reaction to physical disabilities. American Social Reviews 1961;202:241-7.

10 Latner JD, Stunkard AJ. Getting worse: the stigmatization of obese children. Obes Res 2003;11:452-6.

11 Bell SK, Morgan SB. Children's attitudes and behavioral intentions toward a peer presented as obese: does a medical explanation for the obesity make a difference? J Pediatr Psychol 2000;25:137-45.

12 Faith MS, Matz PE, Jorge MA. Obesity-depression associations in the population. J Psychosom Res 2002;53:935-42.

13 Striegel-Moore R, Rodin J. The influence of psychological variables in obesity. In: Brownell KD, Foreyt JP, eds. Handbook of eating disorders: physiology, psychology and treatment of obesity, anorexia and bulimia. New York: Basic Books, 1986:99-121.

14 Stunkard AJ, Wadden TA. Psychological aspects of severe obesity. Am J Clin Nutr 1992;55:524S-32S.

15 O'Neil PM, Jarrell MP. Psychological aspects of obesity and dieting. In: Wadden TA, Vanltallie TB, eds. Treatment of the seriously obese patient. New York: Guildford Press, 1992:252-70.

16 Friedman MA, Brownell KD. Psychological correlates of obesity: moving to the next research generation. Psychol Bull 1995;117:3-20.

17 Achenbach TM. Integrative guide for the $1991 \mathrm{CBCL} / 4-18$, YSR, and TRF profiles. Burlington: University of Vermont Department of Psychiatry, 1991.

18 Stanger C, Achenbach TM, McConaughy SH. Three-year course of behavioral/emotional problems in a national sample of 4- to 16-year-olds: 3 . Predictors of signs of disturbance. J Consult Clin Psychol 1993;61:839-48.

19 Keeping JD, Najman JM, Morrison J, et al. A prospective longitudinal study of social, psychological and obstetric factors in pregnancy: response rates and demographic characteristics of the 8556 respondents. Br J Obstet Gynaecol 1989;96:289-97.

20 Cole TJ, Bellizzi MC, Flegal KM, et al. Establishing a standard definition for child overweight and obesity worldwide: international survey. BMJ 2000;320:1240-3.

21 Tanner JM. Growth at adolescence. Oxford: Blackwell, 1962.

22 Najman JM, Aird R, Bor W, et al. The generational transmission of socioeconomic inequalities in child cognitive development and emotional health. Soc Sci Med 2004;58:1147-58.

23 Magarey AM, Daniels LA, Boulton TJ. Prevalence of overweight and obesity in Australian children and adolescents: reassessment of 1985 and 1995 data against new standard international definitions. Med J Aust 2001;174:561-4.

24 Wardle J, Beales S. Restraint, body image and food attitudes in children from 12 to 18 years. Appetite 1986;7:209-17.

25 Kostanski M, Gullone E. Adolescent body image dissatisfaction: relationships with self-esteem, anxiety, and depression controlling for body mass. J Child Psychol Psychiatry 1998;39:255-62.

26 Tiggemann M. Body-size dissatisfaction: individual differences in age and gender, and relationship with self-esteem. Personality and Individual Differences 1992;13:39-43.

27 McLaren L, Gauvin L. The cumulative impact of being overweight on women's body esteem: a preliminary study. Eat Weight Disord 2002;7:324-7.

28 Wardle J, Waller J, Fox E. Age of onset and body dissatisfaction in obesity. Addict Behav 2002;27:561-73.

29 Roberts RE, Kaplan GA, Shema SJ, Strawbridge WJ. Are the obese at greater risk for depression? Am J Epidemiol 2000;152:163-70. 